\title{
A bleeping nightmare to a dream: Implementation of Hospital at Night
}

\author{
Authors: Jennifer Joiner, ${ }^{*}$ Channa Nadarajah, George Hunter, Saadiq Moledina and Sophie Sterzaker
}

\begin{abstract}
Aims
Hospital at Night (H@N) is a well-established system of providing out-of-hours $(\mathrm{OOH})$ care to patients and has been shown to improve patient safety, reduce mortality and increase productivity. In 2018, Hampshire Hospitals NHS Foundation Trust still had no formal system for $\mathrm{OOH}$ working, causing unmanageable workloads for junior doctors, with repeated trainee surveys and the General Medical Council highlighting this as a concern. This led to unsafe working environments, low morale and a high degree of burnout.
\end{abstract}

\section{Methods}

Initial stakeholder mapping was undertaken to identify key individuals to form a working group and establish a H@N system. This included establishing baseline data by performing an audit of work undertaken by junior doctors out of hours; up-skilling the night practitioner cohort to take on the role of the $\mathrm{H} @ \mathrm{~N}$ coordinator; re-designing the night practitioner rota; educating the nursing and medical workforce about the anticipated changes; designing possible information technology (IT) solutions and drafting standard operating procedures to support H@N. The final H@N system comprised of a coordinator whose role was to triage bleeps, delegate tasks appropriately and undertake clinical tasks; surgical and medical doctors working as a single team; and a structured multidisciplinary handover whereby junior and senior members of the medical, surgical and orthopaedic teams meet to discuss unwell patients.

\section{Results}

Since the new H@N system launched, there has been a reduction in the number of bleeps received by the surgical and medical doctor by $39 \%$ and $74 \%$ respectively. The average time for a bleep to be answered has reduced by $75 \%$. Across all specialties, doctors are spending a larger proportion of their time with unwell patients, improving patient care and safety. A survey of junior doctors has shown that 100\% ( $n=30$ ) found $\mathrm{H} @ N$ had a positive impact and provides a safer environment for both patient and doctors. Feedback has also revealed areas for improvement: more robust

Authors: Basingstoke and North Hampshire Hospital, Hampshire Hospitals NHS Foundation Trust, UK; *Royal College of Physicians chief registrar rota planning for the H@N coordinator; better engagement of ward nursing staff; and further training needs for coordinators.

\section{Conclusion}

Implementing H@N has thus far had a positive impact on the workload of junior doctors out of hours. Longer term data is required in order to assess impact upon patient safety. Future developments include designing an IT system to support H@N, introducing a new escalation sticker and an 'ABC of handover' guide, and expanding the system to weekend working and across both sites within the trust.

\section{Conflict of interest statement}

None. 